\title{
Drawbacks of a Dual Systems Approach to Family Firms: Can We Expand Our Thinking?
}

\author{
Mary F. Whiteside, Fredda Herz Brown
}

\begin{abstract}
Conceptualizing the family firm as a dual system with properties of both the family and the business has prevented the field from fully examining the nature of these firms and has biased our observations and interventions. Too narrow a focus on the contribution of subsystems leads to a stereotyping of subsystem functioning, inconsistent and inadequate analysis of interpersonal dynamics, exaggerated notions of subsystem boundaries, and an underanalysis of whole system characteristics. Each of these drawbacks is discussed, and a beginning view of the family firm as a single entity is presented.
\end{abstract}

Family firms have been described as unique, complex, and challenging social organizations with special characteristics that should be acknowledged by members, advisers, and researchers (Davis and Stern, 1988; Rosenblatt, de Mik, Anderson, and Johnson, 1985; Ward, 1987). To develop an understanding of the nature of family firms, authors have added concepts from family systems theory used by family therapists to concepts from theories of organizations used by social psychologists and organizational development consultants. As a result, the most common view of the family firm is that "in a family owned, family managed firm . . the business system itself is interpenetrated by another system - the family. The degree to which system boundaries overlap, as well as the extent of the interdependence of the two systems, differentiate family firms from other organizations. ... When one looks at a family firm, one is really looking at the interaction of two complex social systems" (McCollom, 1990, p. 251).

Swartz (1989, p. 331) refers to this model as "the dual systems approach." According to him, the business and family systems are seen as separate entities in terms of structure, goals, and tasks. The interaction of these two systems has been illustrated by two circles that have varying degrees of overlap (Benson, Crego, and Drucker, 1990). 
While acknowledging the contribution of the dual systems approach to our enriched understanding of the family firm, Kepner (1983) cautioned that a model that continues to separate business and family has both the potential of being polarized and to polarize. As Hollander and Elman (1988) suggest, dualism tends to support opposition and polarity. In fact, general systems theory, the generic base of most organizational and family systems views, endorses this view. This theory directs us to look at the interaction of different elements in the system with the understanding that the organization that develops out of this interaction has characteristics in its own right that cannot be understood from analysis of the elements individually. Additionally, a change in one area or level will affect other, not necessarily obvious or immediate, areas. It is our view that initial efforts to clarify the special dual systems characteristics of family firms has led us to underemphasize the characteristics of the family firm in its own right. Hollander and Elman (1988) were on target in suggesting that we need to move beyond this focus to one that views the family firm as a "single entity sui generis" (p. 162). It is time in the development of our field to assess the progress we have made using the dual systems notion to understand the nature and functioning of family firms.

\section{Drawbacks of a Dual Systems Approach}

Acknowledgment of the important subsystems in the family firm has been tremendously important in recognizing some of the special characteristics of these firms and in enabling advisers to develop techniques that draw from both family therapy and from management consulting and strategic planning. However, an emphasis on the differences between family and business can lead to three conceptual errors: (1) a stereotyping of subsystem functioning, (2) inconsistent and inadequate analysis of interpersonal dynamics, and (3) exaggerated notions of subsystem boundaries and an underanalysis of whole system characteristics. This paper discusses each of these interrelated drawbacks and then presents a preliminary view of what is needed to view the family firm as a single entity.

Subsystem Stereotyping. As discussed by Hollander and Elman (1988), thinking about family firms has moved from the rational approach to a more systemic model. In the former, the family was viewed as a hindrance to the "rational" functioning of the business. Since the purpose of business was to be logical and profit making, the emotional aspects of the family were an interference that needed to be excluded. While the subsystem approach no longer espouses the need to exclude the family from the business, it has not moved the field much further in terms of the characterizations of the business and the family arenas.

The dual systems view tends to place family tasks, values, and nature in opposition to those of the business. As stated by Ward, "the very nature of 
business often seems to contradict the nature of the family. Families tend to be emotional; businesses are objective" (1987, p. 54). Borwick (1986) and Merkel and Carpenter (1987) delineate differences between families and business organizations in terms of goals, rules for participation, and membership. Benson, Crego, and Drucker (1990) also emphasize the differences between the two systems and remark, "Is it any wonder that when these two basically incompatible systems overlap, as they do in a family business, there is conflict?" (p. 5). Using the two-circle diagram they go on to say that "in a "normal' situation, the overlap is within reasonable limits and thus manageable. . . . When the overlap is excessive conflict can be destructive. . . The excessive carryover of family values to the business is a leading contributor to business failure and family dissension" (1990, p. 6).

Discussions beginning with the assumptions that the family system is primarily "emotion-based," "caring," "sharing," and a "lifetime membership" and that the business system is ideally "unemotional," and "task-based," and has attitudes of "reward performance," and "perform or leave" (Benson, Crego, and Drucker, 1990, p. 6) inject stereotypes into the analysis of the subsystems of the family firm organization. These dichotomies are easily shifted into good versus bad and functional versus nonfunctional, with the family still tending to be considered the system that impedes the functioning of the business. When these differences are exaggerated, particularly when dealing with firms in trouble, there is a tendency toward polarization and a "family-blaming" stance. For instance, Benson, Crego, and Drucker (1990) list a number of common errors made in family firms that they attribute to the excessive influence of the family subsystem on the business. Most of these errors (for example, "childhood sibling rivalry can blossom into full-bloomed internecine warfare," "equal rewards to children regardless of their commitment or ability," "marginally qualified family member may be put in charge of an important operation in order to justify his title" [p. 7]) are more correctly labelled dysfunctional decisions in both the family and management arenas.

Considering the family the emotional arena and the business the rational arena also activates another set of dichotomies related to gender and gender roles. Women have traditionally been the individuals in charge of the family and the domain of relationships, emotion, and process. Men have been viewed as rational, logical, and in charge of work systems. Women still tend to be the invisible members of the family business, functioning behind-the-scenes in the family (Gillis-Donovan and MoynihanBradt, 1990).

What are the consequences to the field if we maintain this perspective? What does it mean when we tend to attribute the traditional characteristics and focus of women to the problematic aspects of family firm functioning? This encourages consultants to view the family as the part of the equation that must be managed-the part whose emotions must be harnessed to 
enrich the business, not impede it. It is easy to understand why such stereotyping exists. When these two systems are viewed so differently in terms of structure and functioning, bringing them together as an explanatory view stretches the idea of integration.

We need to think of the family firm as a laboratory for studying-without the perceptual filter of stereotypes about either subsystem-the integration of work and family systems. For example, when McCollom (1988) gathered research observations of the Esteys family firm, she concluded that "we need to be careful when we pass judgment about 'correct' or 'appropriate' management systems" (p. 414). "The work reported here casts doubt on the line of research that argues that the family dynamics of owners often interfere with business operations and that the appropriate solution is to shield the business from the family. . . . At Esteys . . . the two systems achieved a functional and stable equilibrium" (p. 415). In her analysis McCollom struggled to differentiate characteristics of the Esteys firm that belonged to the business domain versus those belonging to the family domain. She found that these distinctions did not readily fit her observations. Rather, the integration of the Esteys work-family system occurred at a higher level, incorporating aspects of both the family and the management subsystems.

It is useful to view the family firm as its own work system, which is to a greater or lesser extent emotionally and task-oriented. Viewing the family firm as a single entity with both emotional and task characteristics allows us to describe the variations among family firms, to describe the characteristics that differentiate family firms from other types of business organizations, and to develop concepts defining characteristics of healthy versus dysfunctional family firm operations that are useful across disciplines of family firm advisers.

Family firm dynamics include general attributes of human emotional responses, which can come up in all interactions at home or at work. They include specific ways of interacting that we can label as "healthy" or "dysfunctional." In addition, there are dynamics relating to the inevitable consequences of family members working together. These have both emotional and structural impact and can be either healthy or dysfunctional. If we assume that family interactions are "emotional" and business relationships are "rational" we miss these important distinctions.

Business organizations have distinctive styles of interpersonal interactions, established cultures and values, and styles of conflict management. Families also have tasks to accomplish and different management styles and structures to accomplish them. No business is totally task-oriented and no family is totally emotional. The important question is not How do families differ from businesses? but rather Are there common patterns in the ways family firms deal with these tasks of integration? and What are the implications of different types of solutions on the family firm organizational structure? 
Inconsistent and Inadequate Analysis of Interpersonal Dynamics. An important contribution made to the field by the addition of family system ideas has been the inclusion of important nonowner, nonmanager family members in the analysis of family firm interactional dynamics (GillisDonovan and Moynihan-Bradt, 1990; Kepner, 1983). Adding information about family history and dynamics has given us interesting and useful explanations for management structures, business decisions, and areas of tension that otherwise made little sense. However, the error the family therapist can make is to assume that understanding the dynamics of the family is sufficient for dealing with the major dynamic issues of the firm. This view misses, for example, major accommodations and threats stemming from shifts in economic conditions, technical innovations, and the like. In addition, without information about the whole family firm organization, the consultant cannot assess which family issues are insulated from the firm's operations and which family members have minimal connection to the firm. Similar errors can be made from the business side when the adviser assumes that all emotional issues in the firm stem from family problems. When confronted with interpersonal conflicts and tensions, these advisers may say, "This family has emotional problems; send them to therapy. When the problems are fixed they will be able to plan rationally."

One of the special characteristics of the family firm is that within the context of the business environment, relationships among family members will differ from those among nonfamily members. This does not mean that they will be better or worse, just more complex. A family's longer-term relationships and history extending beyond the work environment serve to intensify emotions and may burden them with previous baggage. In addition, people in the firm may fill multiple roles with respect to each other. Multiple role relationships can be confusing but also enriching and very gratifying. If family business consultants see high-intensity and multiplerole relationships among family members at work as a problem per se, they may lose sight of the advantages of family members working together, and they may miss other important sources of dysfunctional relationships in the work environment. That is, the special characteristics of family relationships may tend to obscure some difficulties in the organization and functioning of the family-work system.

Continued dualism in our approach also tends to obscure the difference between dysfunctional expressions of emotion and more general human emotional responses. Business systems of any kind have a code of professionalism or engage in, as Borwick (1986, p. 430) calls it, a "business game" that includes controlled expression of emotion and limitations on intimacy between associates. While these codes may attempt to define behavior in the work system, one does not have to look far to obtain examples of positive and negative emotion affecting work on a routine basis. Emotional processes affect all human exchanges, not just those in 
family businesses. As Friedman (1986) discusses, knowledge of how emotional processes work is useful to all interpersonal bonds. Assessment of communication processes, detoured conflicts, sources of anxiety, and the like are important in any organizational consultation.

It is our view that in a family firm this issue is one of a matter of degree. Family relationships within the firm are more likely to be intense and reactive because of the shared history and multiple-role relationships. However, it has not been demonstrated that family relationships are any more or less likely to be dysfunctional than nonfamily relationships, in or out of business. All of us tend to be emotionally reactive to particular aspects or characteristics of others or to particular situations. While these reactions are usually based on past experiences in our families of origin, they do not always involve family. (For instance, we all tend to emotionally react to authority as we learned to do so in our families.) It is easy when family is present in part of the work system to stop our analysis at this point. However, only sometimes does the appropriate intervention belong in the realm of the family subsystem alone. More frequently, interventions in interpersonal dynamics must be part of the consultant's plan for all issues and be implemented in a variety of subgroupings of family firm members.

For example, in a family firm where the president of the company has a serious alcohol problem, a consultant would naturally be very concerned. Since the owner only drinks outside of the workplace, the consultant using the dualistic approach might view the negative impact of the alcoholism as limited mainly to the upsetting scenes at home. Because analysis informs intervention, this consultant might view the family as the focus of his or her intervention, seeking to have them deal with the alcoholism.

What the consultant would miss would be the patterns of interaction, or enabling, that also support the alcoholism in the family firm organization. Employees, like family members, may experience the president as unpredictable, moody, and self-centered. The consultant may find that a longtime key manager is continually cleaning up after impulsive decisions, similar to the wife at home. In addition, the accountant may be silently concerned about the president's denial of potentially serious tax liabilities. On the board, the consultant may find that the president's sister, a 30 percent shareholder and strong influence, complains regularly about his irresponsibility but continues to approve his questionable schemes and blocks any attempts at strategic planning that would confront her brother's difficulties. If the intervention for the alcoholism were focused solely on a referral to family therapy or to an alcoholism program, the potential for real change in the family firm organization would be limited. If the alcoholism is viewed as a process that affects the family firm, then we would explore how it has been incorporated in all elements of the system. Interventions would involve all aspects with strategies defined, perhaps, by the degree of involvement in the alcoholic process. 
The same line of reasoning is true for any situational disruption or process, such as divorce, death, or serious illness. Analyzing the impact of such events or circumstances as if each belonged to one system with a spread or diffusion to another limits our lens for analysis, conceptualization, and intervention.

Exaggerated Notions of Subsystem Boundaries. When the emphasis is placed on independently structured, bounded subsystems, discussion of boundaries usually focuses on the external boundaries around subsystems. For example, Davis and Stern (1988, p. 75) state, "A basic condition for effective organizational functioning is the maintenance of appropriate boundaries between emotional issues in the family and the tasks required for the successful development and operation of the business." Benson, Crego, and Drucker (1990, p. 9) believe that "conflict resulting from the overlap of family and business systems can not be avoided; however, it can be contained, minimized, and managed by families who are able to establish appropriate boundaries between family and business." Rosenblatt, de Mik, Anderson, and Johnson (1985, p. 125) state, "Diffuse external boundaries between the family and the business seem . . . to be a problem in many business-operating families."

Boundaries are not rigid fences, walls, or other structures separating categories of people. Boundaries need to be examined in terms of four dimensions: structure versus process, density of interconnections, permeability, and clarity. First, when we talk of boundaries we are talking about patterns of organization derived over time from interactional processes. The question of boundaries is much like the "chicken versus the egg" question. Boundaries, like all system structures, derive from process and in turn influence it. When we talk about boundaries as if they were real entities, we miss the interaction of structure and process. For instance, how does a rigid boundary affect decision making among organizational members? Or, how does the process of dealing with each other help to define a structure among family members? When two family members share an office, how does their interaction establish a boundary between them that may be different from that between other family members? Focusing on external boundaries tends to obscure internal alliances and the processes creating them.

The second boundary dimension is the density of interconnections that define boundaries. When the dualistic approach is applied to family firms, we miss the variety of interconnections among members of the firm. Not all family relationships have the same or a single set of boundaries around them. Two family members may share an office, talk to the same clients, jointly supervise employees, and live in the same household. Or they may work in two separate management divisions, see each other only at extended family gatherings, and share responsibility only at the level of the board of directors. These two dyads would be described very differently 
in terms of their access to information, consultation about decisions, cash flow, and time they spend together personally and professionally. Putting a boundary around the family system does not enlarge our view of these different internal relationships and boundaries.

What about a nonfamily member who spends a lot of time with the founder socially and has an office interconnected with him or her? Is this person more or less connected to the founder than the successor? We believe that if we enlarge our view to focus on the family firm as a system, we will be more able to use the concept of a varying density of connections among individuals and the triangles which form to deal with tensions among them.

Density of interconnections also relates to the impact of events in one part of the system on another part of the system. When a family member is precipitously fired by another family member, the ramifications of this process cannot be isolated from future family social events. The more dense the connections, the more powerful the impact of change in the interconnected elements. Just as when a majority of one's contracts are with one big client, there is little insulation from that client's economic crises. Highly interconnected parts of any system have much more mutual influence than less densely connected parts.

The third dimension of boundaries is permeability. Using a dualistic approach, we are more likely to view the boundaries as rigid structures and thus miss the rich insight provided by considering varying degrees of permeability between members or groups. Minuchin (1974) describes boundaries as being rigid, semipermeable, and highly permeable or enmeshed. Observing the boundary around the management constituency in a family business, we might find that no family members are allowed in (rigid boundary), some family members are allowed according to certain rules (semipermeable boundary), or all family members are allowed in as they wish (highly permeable). Companies with formalized job descriptions tend to have more rigid boundaries around roles and functions than do companies where there are few distinctions between owners, managers, and employees. In addition, since family members in family firms have connections in a number of constituencies, the boundaries between those constituencies are, by definition, permeable. Analysis of the ways in which firm members integrate multiple roles and deal with boundaries and differing agendas would make an interesting research project.

The fourth and last aspect of boundaries concerns clarity. This relates to the fact that members of different constituencies may differ on what is important and who is important for the firm. The fact that there are differences within the organization is not necessarily a problem if these are made clear. Davis and Stern $(1988$, p. 83$)$ worry that "there are deepseated contradictions built into the family business that defy resolution." As examples they cite "the excessive power of family members" and "the 
lack of potential for upward mobility (of nonfamily managers)." Not all the boundaries between family and nonfamily members in the family firm are, however, impenetrable. It may be that some family firms are more flexible in this regard than others, and it will be important to examine this across various types of firms. The concern with regard to differences among constituencies seems to center on the lack of clarity regarding expectations and differences. It is thus important to explicitly acknowledge and address these special characteristics and differences. For example, key nonfamily managers need to know from the outset that access to ownership and to the top positions is not available to them. On the other hand, they can be offered attractive motivating employment packages. In other words, the fact that there are certain rigid, or less permeable, boundaries within the system is not necessarily a problem in its own right. If these challenges are stated clearly, there is less chance for confusion and misunderstanding and greater possibility of creative solutions.

\section{Another Approach: The Family Firm as a Single Entity}

General systems theory states that the whole is greater than the sum of its parts. That is, the organization or system that develops out of the interaction of parts cannot be understood by analyzing the parts individually. While this theory underlies most of our work in the family business field, one consequence of the dualistic approach has been to examine family firms as if they were summative systems. We have not put enough attention into describing the organization itself. Lansberg $(1983,1988)$ has made efforts in this direction by focusing his attention on the constituencies of the whole firm, including both family and nonfamily owners and managers. His initial examinations of the structures, goals, and expectations of each of these groupings represent an attempt to move from the dualistic approach.

One could argue (Hollander and Elman, 1988) that it is difficult to describe a holistic system without reference to parts. That is true, but a continued overemphasis on parts will lead to a more serious underanalysis of the whole. We need to begin examining the characteristics of family firms. What are they? Is there a typology of them? Along what dimensions can they be observed, described, and analyzed? How do they differ from and resemble other types of firms? We need to study firms in particular areas, like service or manufacturing, and analyze if and how they differ from one another. Until we broaden our lens to look at the whole, we will continue to focus on differences, distinctions, and uniqueness without a context to embrace them.

While the dual systems approach focuses on the overlap of two systems, a single entity approach focuses on describing the new organization created by the integration of parts. In order to do this, we must focus on both the macro and micro levels, using wide and narrow lenses respectively. Using 
the wide lens, we can draw a picture that includes the total membership of all constituencies. This might be thought of as the family firm "supra system." For this view, all family members, including at least three generations, are important foci-as are nonfamily owners, managers, and employees. In addition, we might include those people involved in the ongoing input or output of the business, for example, the key vendors, advisers, lending institutions, and so on. This perspective is a useful starting point for gathering data for assessment or research purposes, but it is far too inclusive to be useful in determining whom one talks with when consulting or in determining the impact of key planning decisions.

A narrow lens can focus on the central core of the family firm organization, which cuts across and is generally inclusive of all the constituencies. Davis (1983) discusses a similar idea, calling this group the "sentient system":

The family business is made up of a system of interrelated individuals, both family members and nonfamily employees. A subsystem of this system is the sentient system that has the family at its core and is made of individuals bound by strong emotional and loyalty bonds. The sentient system will generally include nonfamily members who are "drawn into" and become subject to the basic organizing rules of the family. . . .

In the family business, the family paradigm extends to the sentient system, which then interacts with the task system to produce behaviors that are unique to this form of organization [pp. 51-52].

While Davis does not delineate how membership in this system is derived, the idea of a core or sentient organization allows us-without referring solely to family or to business-to describe the unique characteristics of family firms as well as to distinguish dimensions relating to differences among family firms. For example, firms will vary in terms of the number of family and nonfamily members in the core organization. They will probably differ in terms of the way in which finances are handled. Some family firms may make few distinctions between family money and business money, while others may consider them to be quite different. Firms may also vary in terms of the amount of information given to family members outside the business and to nonfamily managers in the firms. Firms vary in terms of who makes decisions. And, the membership of the core organization may vary over time as the family firm changes in goals and structure.

We suggest that the core organization of the family firm comprises a highly interconnected group of individuals that includes both family and nonfamily members. These connections can be studied by examining decision-making patterns, information flow, cash flow, operational procedures, interactions around critical events, conflicts, crises, and patterns of ownership. This core organization has a distinctive style and structure and is more than just a blending of the constituency subsystems. 
These structures and patterns need to be assessed when we are determining issues of function and dysfunction in the firm. While family business consulting has evolved from dealing with firms in trouble, it is not at all clear what the continuum of "in trouble" looks like and how interventions may differ along such a continuum. Ward (1987, p. 55) states that "well-managed businesses and healthy families do share many positive, constructive traits." But he goes on to say that his suggestions for the successful integration of the family firm are directed at healthy families because "families with serious emotional problems will find it difficult to focus on the planning process and have productive meetings" (p. 131). We believe we need to go a step farther by observing and comparing family firms that are defined as functional with those viewed as dysfunctional on a number of variables by their advisers. For example, do we see frustration and blockage in decision making, in communication among key managers, in operational procedures, and in finance? In other words, do we see the same synergy of dysfunctional processes throughout a firm's constituencies that we see with healthy firms?

All advisers deal with clients over the whole continuum of functional, midrange, and dysfunctional behavior. Each field has its own version of a "sick system." What are the red flags that indicate to each of the disciplines that this firm is having difficulty? Is there any consistency in defining the dysfunction? Are there different types of organizational structures for the family firm that reflect particular combinations of family style, type of industry, developmental stage of the firm, and economic conditions?

Our experience is that these "red flagged" firms-the ones that are frustrating to deal with-tend to stimulate analyses and interventions that separate family and business. To us, however, it is not a question of the family problems contaminating the business organization. It may be a situation in which the business organization that has developed in certain family firms engenders more difficulties than in others. Difficulties may stem from chronic dysfunctional interactional or structural processes. They may stem from current situational or developmental changes or crises. Or, they may relate to historical legacies of unresolved emotional reactions. It is up to us to broaden our analysis so that we can examine these issues.

\section{Conclusion}

In much of the theoretical work to date, the family firm has been conceptualized as a dual system with properties of both the family and the business. It is our contention that this conceptualization may have prevented us from fully examining the nature of these firms and from exploring how this view has biased observations and interventions. This paper has explored several areas in which the subsystem focus has limited our view of the family firm as a whole. When viewed as a single system, the family firm 
organization can be described as having both task and emotional characteristics and as evolving a distinct organizational style and structure. We need more research and theory that look at similarities and differences among many types of family firms as well as between family and nonfamily firms. In addition, we need to continue to clarify our assumptions about what makes for a firm's health or dysfunction, both on subsystem and whole system levels.

\section{References}

Benson, B., Crego, E. T., and Drucker, R. H. Your Family Business: A Success Guide for Growth and Survival. Homewood, Ill.: Dow Jones-Irwin, 1990.

Borwick, I. "The Family Therapist as Business Consultant." In L. C. Wynne, S. H. McDaniel, and T. T. Weber (eds.), Systems Consultation: A New Perspective for Family Therapy. New York: Guilford Press, 1986.

Davis, P. "Realizing the Potential of the Family Business." Organizational Dynamics, 1983, 12 (1), 47-56.

Davis, P., and Stern, D. "Adaptation, Survival, and Growth of the Family Business: An Integrated Systems Perspective." Human Relations, 1980, 34 (4), 207-224. (Reprinted in Family Business Review, 1988, 1 (1), 69-85.)

Friedman, E. H. "Emotional Process in the Marketplace: The Family Therapist as Consultant with Work Systems." In L. C. Wynne, S. H. McDaniel, and T. T. Weber (eds.), Systems Consultation: A New Perspective for Family Therapy. New York: Guilford Press, 1986.

Gillis-Donovan, J., and Moynihan-Bradt, C. "The Power of Invisible Women in the Family Business." Family Business Review, 1990, 3 (2), 153-167.

Hollander, B. S., and Elman, N. S. "Family-Owned Businesses: An Emerging Field of Inquiry." Family Business Review, 1988, 1 (2), 145-164.

Kepner, E. "The Family and the Firm: A Coevolutionary Perspective." Organizational Dynamics, 1983, 12 (1), 57-70.

Lansberg, I. "Managing Human Resources in Family Firms: The Problem of Institutional Overlap." Organizational Dynamics, 1983, 12 (1), 39-46.

Lansberg, I. "The Succession Conspiracy." Family Business Review, 1988, 1 (2), 119-143.

McCollom, M. E. "Integration in the Family Firm: When the Family System Replaces Controls and Culture." Family Business Review, 1988, 1 (4), 399-417.

McCollom, M. E. "Problems and Prospects in Clinical Research on Family Firms." Family Business Review, 1990, 3 (3), 245-262.

Merkel, W. T., and Carpenter, L. J. "A Cautionary Note on the Application of Family Therapy Principles to Organizational Consultation." American Journal of Orthopsychiatry, 1987, 57 (1), 111-115.

Minuchin, S. Families and Family Therapy. Cambridge, Mass.: Harvard University Press, 1974.

Rosenblatt, P. C., de Mik, L., Anderson, R. M., and Johnson, P. A. The Family in Business: Understanding and Dealing with the Challenges Entrepreneurial Families Face. San Francisco: Jossey-Bass, 1985.

Salganicoff, M. "Women in Family Businesses: Challenges and Opportunities." Family Business Review, 1990, 3 (2), 125-137.

Swartz, S. "The Challenges of Multidisciplinary Consulting to Family-Owned Businesses." Family Business Review, 1989, 2 (4), 329-339.

Ward, J. L. Keeping the Family Business Healthy: How to Plan for Continuing Growth, Profitability, and Family Leadership. San Francisco: Jossey-Bass, 1987. 
Mary F. Whiteside, Ph.D., is a psychologist and consultant affiliated with the Ann Arbor Center for the Family, Ann Arbor, Michigan.

Fredda Herz Brown, Ph.D., is a psychologist and principal with Metropolitan Family Business Associates, Leonia, New Jersey. 